\title{
Current understanding of adult neurogenesis in the mammalian brain: how does adult neurogenesis decrease with age?
}

Yoshitaka Kase ${ }^{1,2}$, Takuya Shimazaki ${ }^{1}$ and Hideyuki Okano ${ }^{1 *}$

\begin{abstract}
Adult neurogenesis occurs throughout life in restricted brain regions in mammals. However, the number of neural stem cells (NSCs) that generate new neurons steadily decreases with age, resulting in a decrease in neurogenesis. Transplantation of mesenchymal cells or cultured NSCs has been studied as a promising treatment in models of several brain injuries including cerebral infarction and cerebral contusion. Considering the problems of host-versusgraft reactions and the tumorigenicity of transplanted cells, the mobilization of endogenous adult NSCs should be more feasible for the treatment of these brain injuries. However, the number of adult NSCs in the adult brain is limited, and their mitotic potential is low. Here, we outline what we know to date about why the number of NSCs and adult neurogenesis decrease with age. We also discuss issues applicable to regenerative medicine.
\end{abstract}

Keywords: Adult neurogenesis, Aging, Neural stem cell, Subgranular zone, Transit amplifying progenitor cell, Ventricular-subventricular zone

\section{Background}

In mammals, neural stem cells (NSCs) in the early embryonic period are called neuroepithelial cells. Neuroepithelial cells self-renew symmetrically on the ventricular surface $[1,2]$. This symmetric division increases the number of neuroepithelial cells lining the ventricular surface and enlarges the ventricular zone (VZ) [3]. After the neural tube is closed, neuroepithelial cells are converted into radial glial cells with long radial fibers, and asymmetric cell division that allows the generation of a large number of neurons also begins [4]. After the neurogenic period, these radial glial cells differentiate into glia, astrocytes with NSC properties, or ependymal cells with cilia [5].

In the adult brain, most NSCs are quiescent. However, NSCs in the ventricular-subventricular zone (V-SVZ)

\footnotetext{
* Correspondence: hidokano@keio.jp

1 Department of Physiology, Keio University School of Medicine, 35

Shinanomachi, Shinjuku-ku, Tokyo 160-8582, Japan

Full list of author information is available at the end of the article
}

and subgranular zone (SGZ) of the hippocampal dentate gyrus (DG) slowly divide to generate transit amplifying progenitor cells (TAPs) via a state called activated neural stem cells (aNSC) and thus generate new neurons [6-8]. Such adult neurogenesis in the mammalian brain was first suggested in the 1960s [9], and neurogenesis has been found to occur primarily in the V-SVZ and SGZ throughout life [10-15]. New neurons generated in these two neurogenic areas are incorporated into neural circuits and play important roles. For example, in rodents, new neurons born in the V-SVZ migrate into the olfactory bulb via the rostral migratory stream (RMS), in which newly generated neurons migrate along each other as oriented chains and are encapsulated by a complex network of astrocyte tunnels [14, 16]. The attenuation of adult neurogenesis in the V-SVZ has been reported to cause abnormal olfactory and sexual behavior in mice [17]. In addition, new neurons generated in the SGZ are also integrated into DG neural circuits and

(c) The Author(s). 2020 Open Access This article is licensed under a Creative Commons Attribution 4.0 International License, which permits use, sharing, adaptation, distribution and reproduction in any medium or format, as long as you give

appropriate credit to the original author(s) and the source, provide a link to the Creative Commons licence, and indicate if changes were made. The images or other third party material in this article are included in the article's Creative Commons licence, unless indicated otherwise in a credit line to the material. If material is not included in the article's Creative Commons licence and your intended use is not permitted by statutory regulation or exceeds the permitted use, you will need to obtain permission directly from the copyright holder. To view a copy of this licence, visit http://creativecommons.org/licenses/by/4.0/ 
play an important role in the formation of short-term memory. The attenuation of neurogenesis in the mouse SGZ has been reported to result in the impairment of new memory formation [7, 18-23]. These new neurons are also important for the formation of spatial memories [24-27]. Furthermore, new integrated neurons in the DG have the function of organizing past memories and alleviating the stress response [28, 29]. However, adult neurogenesis decreases with age, mainly due to a decrease in NSCs and TAPs [14, 30, 31]. Several studies have reported that this reduction is likely to be caused by decreases in extrinsic signals that support the proliferation of NSCs, including mitotic signals such as EGF and FGF-2 [32, 33], and increases in systemic pro-aging factors [34].

Here, we review adult NSCs and neurogenesis and the mechanisms of their age-related declines. We will also describe the challenges of NSC activation as a therapeutic strategy.

\section{Main text}

\section{Origin of adult NSCs}

NSCs are actively self-renewing, allowing the generation of a large number of neurons and glia during central nervous system development [35] and thus rapid cerebral development during the embryonic stage. Although the growth of the brain continues even after birth, it slows quickly even in the V-SVZ and SGZ and is completed by approximately 4 weeks after birth in mice. After this developmental phase, active neurogenesis via TAPs generated from slowly dividing NSCs occurs only in the V-SVZ and SGZ [14, 22, 30, 31, 36-38]. It was previously believed that these slowly dividing adult NSCs merely remain actively dividing embryonic NSCs [39]. However, it was recently reported that slowly dividing embryonic NSCs with high p57 expression become dormant adult NSCs in the V-SVZ [40]. In addition, it has been suggested that the cleavage plane orientation of embryonic radial glial cells regulates the number of adult NSCs in the lateral ganglionic eminence [41]. In the mouse SGZ, NSCs originate from Sonic Hedgehogresponsive progenitors expressing Gli1 located in the ventral hippocampus during late gestation [42].

\section{Age-dependent decrease in neural stem cells and adult neurogenesis}

Although the biological significance of adult hippocampal neurogenesis in humans is still under debate [43, 44 , the physiological roles of adult neurogenesis in other species are evident.

On the other hand, the number of NSCs decreases with age in both the V-SVZ [14, 22, 30, 31, 36-38] and SGZ [38, 45, 46], resulting in a reduction in neurogenesis. What factors contribute to the decrease in adult neurogenesis upon aging? The expression of EGF and FGF, which are well-known mitogens that promote the self-renewal of aNSCs and TAPs, in the brain decreases with age, which may be a cause of the agedependent decline in neurogenesis [32, 33, 42].

It has also been reported that the sharing of blood circulation between old and young mice (parabiosis) improves brain function and other functions in old mice [47]. The circulation of blood from young mice through the cardiovascular system of aged mice promotes neurogenesis in the SGZ and activates neural functions. In this study, C-C motif chemokine ligand 11 (CCL11) was reported to be an aging-promoting factor. $\beta 2$-microglobulin has also been identified as a pro-aging factor that promotes age-dependent declines in neurogenesis in the SGZ and cognitive function [48]. In contrast, another study using parabiosis identified GDF11 (a circulating TGF- $\beta$ family member) as an anti-aging factor that can improve the cerebral vasculature and enhance neurogenesis in the V-SVZ of aged mice [49]. More recently, Yousef et al. showed that an age-dependent increase in the soluble form of vascular cell adhesion molecule 1 (VCAM1), which is a protein that promotes interaction between blood vessels and immune cells in plasma, may cause an age-related decrease in hippocampal neurogenesis via an increase in the inflammatory transcriptional profile, including the transcription of VCAM1, in endothelial cells in the mouse hippocampus [50]. The age-related decrease in adult neurogenesis caused by changes in the components of plasma is likely to be mediated at least in part by changes in DNA methylation status. It has been shown that an age-dependent decrease in the expression of ten-eleven translocation methylcytosine dioxygenase 2 (Tet2), which catalyzes the production of 5hydroxymethylcytosine, is one of the causes of the age-related decline in neurogenesis in the mouse SGZ [51]. Interestingly, in this study, heterochronic parabiosis restored Tet2 expression and neurogenesis in the aged hippocampus.

Adult NSCs in the V-SVG and SGZ reside in specialized microenvironments referred to as stem cell niches, which are essential for the maintenance of NSCs and the control of neurogenesis. A number of studies have suggested that blood vessels are an integral part of stem cell niches. For instance, the vascular endothelial growth factor VEGF is known to be a glycoprotein that promotes angiogenesis and has a positive effect on neurogenesis [52-54].

In addition, cerebral blood volume in the DG has been shown to be correlated with neurogenesis in the SGZ [55]. Thus, vascular aging may slow the growth of NSCs and TAPs and diminish their ability to generate new neurons. Indeed, it has been shown that the VEGF level in the hippocampus decreases upon aging in rats [56]. 
Proteostasis has also been shown to be important for the regulation of NSC proliferation and differentiation. In the adult brain, NSCs in a relatively quiescent state need to become aNSCs and self-renew or divide into TAPs to generate new neurons. Leeman et al. showed that aNSCs have active proteasomes but that quiescent NSCs (qNSCs) accumulate protein aggregates, many of which are stored in large lysosomes. Upon aging, qNSCs display lysosomal defects, increased accumulation of protein aggregates, and decreased ability to be activated. It has been reported that enhancing the lysosomal pathway in aged qNSCs improves their ability to be activated [57].

Mitochondrial dysfunction may also be a cause of the age-related decline in adult neurogenesis. In the V-SVZ, mitochondrial abundance and the oxygen consumption rate decrease with age, but the mutation rate of mitochondrial DNA in aged neural progenitor cells does not increase [58]. It has also been suggested that mitochondrial dysfunction in the SGZ induced by aging may be responsible for decreased neurogenesis [59].

Oxygen levels, which affect oxidative stress via the production of reactive oxygen species in stem cell niches, alter the fate of NSCs. HIF- $1 \alpha$ responds to hypoxic conditions and promotes NSC proliferation. HIF$1 \alpha$ regulates adult neurogenesis by promoting $\mathrm{NSC} /$ progenitor cell proliferation and differentiation via Wnt/ $\beta$-catenin signaling [60]. Another study revealed that NSC-encoded HIF- $1 \alpha$ is essential for the maintenance of adult neurogenesis in the V-SVZ and demonstrated that NSCs within the SVZ maintain the integrity of their vascular niche via HIF-1 $\alpha$ signaling [61].
There have also been studies on sex hormones. While androgen, a male hormone, has been shown to positively regulate neurogenesis in the SGZ of male mice, circulating androgen levels decrease with age. Interestingly, the administration of androgen increases adult neurogenesis only in young male rats but not in female or aged male rats, even though androgen receptor expression increases in the hippocampus of both male and female rats after middle age. Aging may result in a loss of reactivity to androgen itself. Estrogen also increases hippocampal adult neurogenesis in young and nulliparous female rats but not after middle age. On the other hand, estrogen does not promote hippocampal neurogenesis in male rats [62-65].

In addition to sex hormones, adrenal steroids have been shown to negatively regulate neurogenesis in the SGZ [66]. Furthermore, corticosteroids have been shown to cause an age-related decline in neurogenesis in the SGZ. It has also been reported that decreasing corticosteroid levels induced by removing the adrenal gland promotes neurogenesis in the SGZ of aged mice SGZ [67].

Cerebrospinal fluid, which is primarily produced by the choroid plexus and contains a number of signaling molecules, also changes with age. NSCs in the V-SVZ are in contact with cerebrospinal fluid, and age-dependent changes in the secretome in the lateral ventricular choroid plexus (LVCP) are also important for NSC regulation. Silva-Vargas et al. conducted transcriptome and proteomic assays of the LVCP secretome in young and aged mice and found that an age-dependent reduction in BMP5 and IGF1 secretion from the LVCP caused a decrease in the proliferative capacity of NSCs [68].

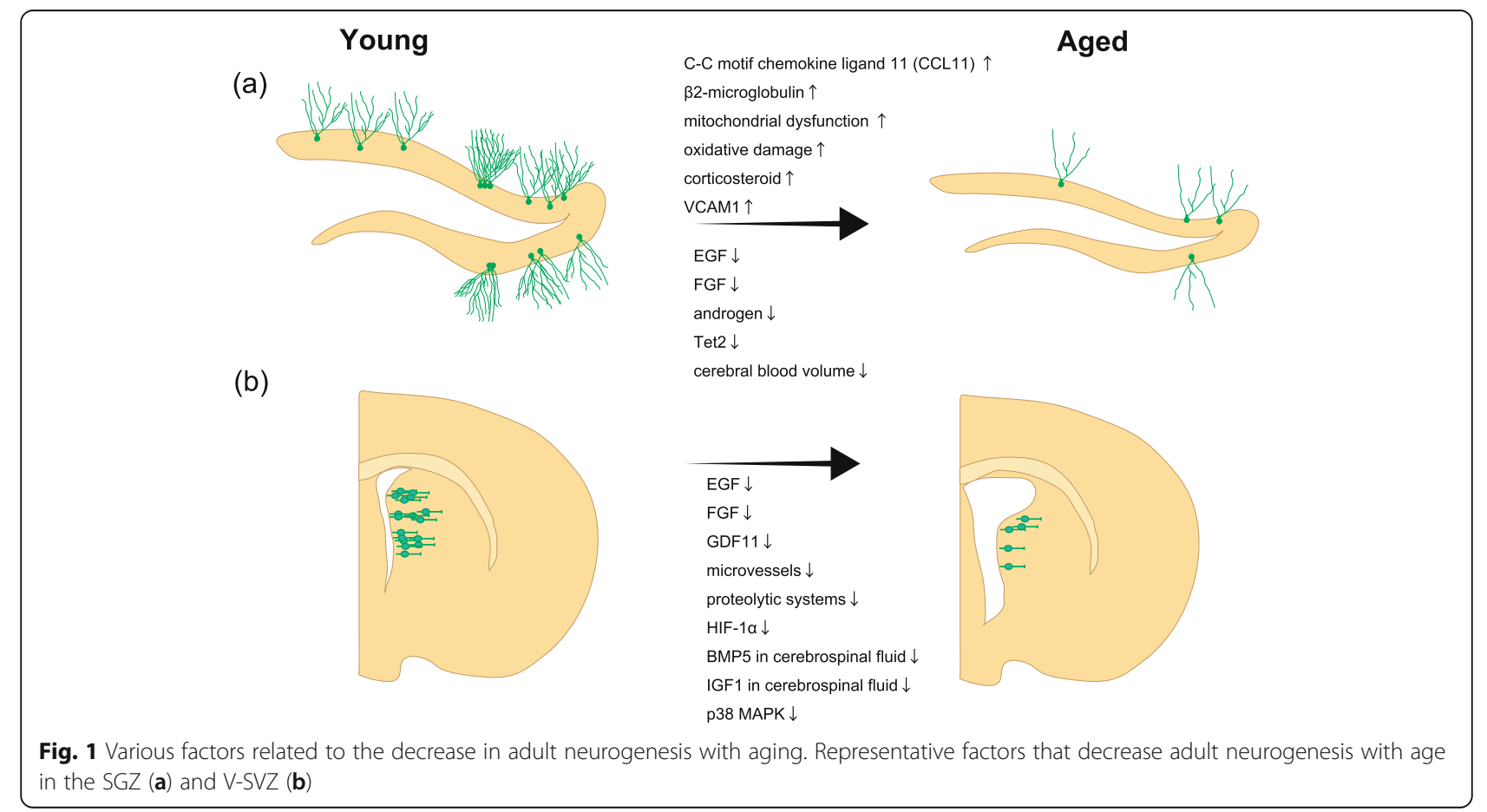




\section{Challenges of regenerative therapy involving the activation of adult NSCs}

Adult neurogenesis is reduced due to decreases in the activity and number of NSCs caused by various factors as described above (Fig. 1). However, adult neurogenesis in the V-SVZ and DG is essential, albeit slightly, for normal brain function, such as odor discrimination, sexual behavior, and the formation of new short-term memories.

The activation of dormant NSCs to promote neurogenesis should be an effective regenerative medicine strategy for neural loss due to cerebrovascular disorders, traumatic brain injury, and neurodegenerative diseases. The activation of adult NSCs transiently increases the number of new neurons but ultimately leads to the depletion of NSCs, indicating that the supply of new neurons is limited $[69,70]$. This mechanism has also been proposed in epilepsy models [71]. In epileptic seizures, abnormal firing stimulates NSCs, temporarily increasing the division of NSCs and promoting neurogenesis. However, as seizures reoccur, NSCs are depleted, eventually leading to neuronal depletion. It is not clear whether the depletion of residual NSCs induced by the activation of NSCs is harmful over a long period of time after treatment and whether long-term neurogenesis is promoted. We have found that a decrease in p38 MAPK expression in the V-SVZ, one of the areas of neurogenesis, is responsible for the age-dependent decrease in the self-proliferation of TAPs and that maintaining its expression can promote long-term adult neurogenesis without depleting NSCs [38]. Therefore, the amplification and mobilization of TAPs could be a better approach for regenerative brain repair.

\section{Conclusion}

Since the existence of adult NSCs and adult neurogenesis was confirmed, studies on adult neurogenesis have been intensively conducted with the expectation of applying NSCs and neurogenesis for regenerative medicine.

Although the mobilization of endogenous NSCs has been studied as one of regenerative approaches to restore lost brain function in cerebrovascular diseases, traumatic brain injuries, neurodegenerative diseases, etc., there are still many issues to be solved, such as the depletion of NSCs and the directed migration of new neurons. From a fundamental point of view, identifying the regulatory mechanisms of adult neurogenesis and its age-related decline will undoubtedly lead to future regenerative medicine strategies.

\section{Abbreviations}

aNSC: Activated neural stem cells; CCL11: C-C motif chemokine ligand 11; DG: Dentate gyrus; HIF: Hypoxia-inducible transcriptional factor;

NSCs: Neuronal stem cells; qNSCs: Quiescent neural stem cells; RMS: Rostral migratory stream; SGZ: Subgranular zone; TAPs: Transit amplifying progenitor cells; Tet2: Ten-eleven translocation methylcytosine dioxygenase 2; VCAM1: Vascular cell adhesion molecule 1; V-SVZ: Ventricular-subventricular zone; VZ: Ventricular zone

Authors' contributions

$\mathrm{KY}$ wrote the manuscript, and TS and $\mathrm{HO}$ edited and finalized it. All authors approved the final manuscript.

\section{Funding}

This work was supported by research grants from The General Insurance Association of Japan (to Y.K.) and the Program for the Advancement of Research in Core Projects on Longevity of the Keio University Global Research Institute from Keio University (to H.O.).

Ethics approval and consent to participate

Not applicable.

Consent for publication

Not applicable.

\section{Competing interests}

The authors declare that they have no competing interests.

\section{Author details}

'Department of Physiology, Keio University School of Medicine, 35

Shinanomachi, Shinjuku-ku, Tokyo 160-8582, Japan. ${ }^{2}$ Department of Geriatric Medicine, Graduate School of Medicine, The University of Tokyo, Bunkyo-ku, Tokyo 113-8655, Japan.

Received: 19 February 2020 Accepted: 8 June 2020

Published online: 18 June 2020

\section{References}

1. Pevny L, Rao MS. The stem-cell menagerie. Trends Neurosci. 2003;26(7):351-9.

2. Kosodo Y, Suetsugu T, Suda M, Mimori-Kiyosue Y, Toida K, Baba SA, et al. Regulation of interkinetic nuclear migration by cell cycle-coupled active and passive mechanisms in the developing brain. EMBO J. 2011;30(9):1690-704.

3. Alvarez-Buylla A, García-Verdugo JM, Tramontin AD. A unified hypothesis on the lineage of neural stem cells. Nat Rev Neurosci. 2001;2(4):287-93. https://doi.org/10.1038/35067582.

4. Kriegstein A, Alvarez-Buylla A. The glial nature of embryonic and adult neural stem cells. Annu Rev Neurosci. 2009;32:149-84.

5. Spassky N, Merkle FT, Flames N, Tramontin AD, García-Verdugo JM, AlvarezBuylla A. Adult ependymal cells are postmitotic and are derived from radial glial cells during embryogenesis. J Neurosci. 2005;25(1):10-8.

6. Kempermann G, Gage FH. New nerve cells for the adult brain. Sci Am. 1999; 280(5):48-53.

7. Encinas JM, Michurina TV, Peunova N, Park JH, Tordo J, Peterson DA, Fishell G, Koulakov A, Enikolopov G. Division coupled astrocytic differentiation and age related depletion of neural stem cells in the adult hippocampus. Cell Stem Cell. 2011;8:566-79.

8. Ming GL, Song H. Adult neurogenesis in the mammalian brain: significant answers and significant questions. Neuron. 2011;70:687-702.

9. Altman J. Autoradiographic study of degenerative and regenerative proliferation of neuroglia cells with tritiated thymidine. Exp Neurol. 1962:5:302-18.

10. Pincus DW, Keyoung HM, Harrison-Restelli C, Goodman RR, Fraser RA, Edgar $M$, et al. Fibroblast growth factor-2/brain-derived neurotrophic factorassociated maturation of new neurons generated from adult human subependymal cells. Ann Neurol. 1998;43(5):576-85.

11. Roy NS, Benraiss A, Wang S, Fraser RA, Goodman R, Couldwell WT, et al. J Neurosci Res. 2000;59(3):321-31.

12. Okano H. Stem cell biology of the central nervous system. J Neurosci Res. 2002;69(6):698-707.

13. Okano H, Sawamoto K. Neural stem cells: involvement in adult neurogenesis and CNS repair. Philos Trans R Soc Lond B Biol Sci. 2008; 363(1500):2111-22.

14. Gage FH. Mammalian neural stem cells. Science. 2000;287(5457):1433-8. 
15. Eriksson PS, Perfilieva E, Björk-Eriksson T, Alborn AM, Nordborg C, Peterson DA, et al. Neurogenesis in the adult human hippocampus. Nat Med. 1998; 4(11):1313-7.

16. Obernier K, Cebrian-Silla A., Thomson, M., Parraguez, J. I., Anderson, R., Guinto, $C$., et al. Adult neurogenesis is sustained by symmetric self-renewal and differentiation. Cell Stem Cell. 2018;22(2):221-234.e8.

17. Carleton A, Petreanu LT, Lansford R, Alvarez-Buylla A, Lledo PM. Becoming a new neuron in the adult olfactory bulb. Nat Neurosci. 2003;6(5):507-18.

18. Sakamoto M, Imayoshi I, Ohtsuka T, Yamaguchi M, Mori K, Kageyama R. Continuous neurogenesis in the adult forebrain is required for innate olfactory responses. Proc Natl Acad Sci U S A. 2011;108(20):8479-84.

19. Yassa MA, Stark CE. Pattern separation in the hippocampus. Trends Neurosci. 2011;34:515-25.

20. Deng W, Aimone J, Gage FH. New neurons and new memories: how does adult hippocampal neurogenesis affect learning and memory? Nat Rev Neurosci. 2010;11:339-50.

21. Kempermann G. The neurogenic reserve hypothesis: what is adult hippocampal neurogenesis good for? Trends Neurosci. 2008;31:163-9.

22. Marin Burgin A, Schinder AF. Requirement of adult born neurons for hippocampus dependent learning. Behav Brain Res. 2012;227:391-9.

23. Aimone JB, Li Y, Lee SW, Clemenson GD, Deng W, Gage FH. Regulation and function of adult neurogenesis: from genes to cognition. Physiol Rev. 2014; 94(4):991-1026.

24. McHugh TJ, Jones MW, Quinn JJ, Balthasar N, Coppari R, Elmquist JK, et al. Dentate gyrus NMDA receptors mediate rapid pattern separation in the hippocampal network. Science. 2007;317(5834):94-9. https://doi.org/10. 1126/science.1140263.

25. Clelland CD, Choi M, Romberg C, Clemenson GD Jr, Fragniere A, Tyers $P$, et al. A functional role for adult hippocampal neurogenesis in spatial pattern separation. Science. 2009;325(5937):210-3.

26. Sahay A, Scobie KN, Hill AS, O'Carroll CM, Kheirbek MA, Burghardt NS, et al. Increasing adult hippocampal neurogenesis is sufficient to improve pattern separation. Nature. 2011:472(7344):466-70

27. Nakashiba T, Cushman JD, Pelkey KA. Renaudineau, S., Buhl, D. L., McHugh, T. J., et al. Young dentate granule cells mediate pattern separation, whereas old granule cells facilitate pattern completion. Cell. 2012;149(1):188-201.

28. Santarelli L, Saxe M, Gross C, Surget A, Battaglia F, Dulawa S, et al. Requirement of hippocampal neurogenesis for the behavioral effects of antidepressants. Science. 2003;301(5634):805-9.

29. Snyder JS, Soumier A, Brewer M, Pickel J, Cameron HA. Adult hippocampal neurogenesis buffers stress responses and depressive behaviour. Nature. 2011;476(7361):458-61.

30. Capilla-Gonzalez V, Herranz-Pérez V, García-Verdugo JM. The aged brain: genesis and fate of residual progenitor cells in the subventricular zone. Front Cell Neurosci. 2015;9:365.

31. Bonaguidi MA, Wheeler MA, Shapiro JS, Stadel RP, Sun GJ, Ming GL, et al. In vivo clonal analysis reveals self-renewing and multipotent adult neural stem cell characteristics. Cell. 2011;145(7):1142-55.

32. Conover JC, Todd KL. Development and aging of a brain neural stem cell niche. Exp. Gerontol. 2017;94:9-13.

33. Seib DR, Martin-Villalba A. Neurogenesis in the normal ageing hippocampus: a mini-review. Gerontology. 2015;61(4):327-35.

34. Bond AM, Ming GL, Song $H$. Adult mammalian neural stem cells and neurogenesis: five decades later. Cell Stem Cell. 2015;17(4):385-95.

35. Fuentealba LC, Rompani SB, Parraguez Jl, Obernier K, Romero R, Cepko $\mathrm{CL}$, et al. Embryonic origin of postnatal neural stem cells. Cell. 2015; 161(7):1644-55.

36. Ben Abdallah NM, Slomianka L, Vyssotski AL, Lipp HP. Early age-related changes in adult hippocampal neurogenesis in C57 mice. Neurobiol Aging. 2010;31(1):151-61.

37. Kempermann G. Activity dependency and aging in the regulation of adult neurogenesis. Cold Spring Harb Perspect Biol. 2015;7(11):a018929.

38. Kase Y, Otsu K, Shimazaki T, Okano H. Involvement of p38 in age-related decline in adult neurogenesis via modulation of Wnt signaling. Stem Cell Reports. 2019;12(6):1313-28.

39. Merkle FT, Tramontin AD, García-Verdugo JM, Alvarez-Buylla A. Radial glia give rise to adult neural stem cells in the subventricular zone. Proc Natl Acad Sci U S A. 2004;101(50):17528-32.

40. Furutachi S, Miya H, Watanabe T, Kawai H, Yamasaki N, Harada Y, et al. Slowly dividing neural progenitors are an embryonic origin of adult neura stem cells. Nat Neurosci. 2015;18(5):657-65.
41. Falk S, Bugeon S, Ninkovic J, Pilz GA, Postiglione MP, Cremer H, et al. Timespecific effects of spindle positioning on embryonic progenitor pool composition and adult neural stem cell seeding. Neuron. 2017;93(4):777791.e3.

42. Li G, Fang L, Fernández G, Pleasure SJ. The ventral hippocampus is the embryonic origin for adult neural stem cells in the dentate gyrus. Neuron. 2013;78(4):658-72

43. Kempermann G, Gage FH, Aigner L, Song H, Curtis MA, Thuret $\mathrm{S}$, et al. Human adult neurogenesis: evidence and remaining questions. Cell Stem Cell. 2018;23(1):25-30.

44. Sorrells SF, Paredes MF, Cebrian-Silla A, Sandoval K, Qi D, Kelley KW, et al. Human hippocampal neurogenesis drops sharply in children to undetectable levels in adults. Nature. 2018;555(7696):377-81.

45. Kuhn HG, Dickinson-Anson H, Gage FH. Neurogenesis in the dentate gyrus of the adult rat: age-related decrease of neuronal progenitor proliferation. J Neurosci. 1996;16(6):2027-33.

46. Lee SW, Clemenson GD, Gage FH. New neurons in an aged brain. Behav Brain Res. 2012;227(2):497-507.

47. Villeda SA, Luo J, Mosher Kl, Zou B, Britschgi M, Bieri G, et al. The ageing systemic milieu negatively regulates neurogenesis and cognitive function. Nature. 2011:477(7362):90-4.

48. Smith LK, He Y, Park JS, Bier G, Snethlage CE, Lin K, et al. $\beta 2$-microglobulin is a systemic pro-aging factor that impairs cognitive function and neurogenesis. Nat Med. 2015;21(8):932-7.

49. Katsimpardi L, Litterman NK, Schein PA, Miller CM, Loffredo FS, Wojtkiewicz $G R$, et al. Vascular and neurogenic rejuvenation of the aging mouse brain by young systemic factors. Science. 2014;344(6184):630-4.

50. Yousef H, Czupalla CJ, Lee D, Chen MB, Burke AN, Zera KA, et al. Aged blood impairs hippocampal neural precursor activity and activates microglia via brain endothelial cell VCAM1. Nat Med. 2019:25(6):988-1000.

51. Gontier G, Iyer M, Shea JM. Bieri, G., Wheatley, E. G., Ramalho-Santos, M., et al. Tet2 rescues age-related regenerative decline and enhances cognitive function in the adult mouse brain. Cell Rep. 2018;22(8):1974-81.

52. Cao L, Jiao X, Zuzga DS, Liu Y, Fong DM, Young D, et al. VEGF links hippocampal activity with neurogenesis, learning and memory. Nat Genet. 2004:36(8):827-35

53. Jin K, Zhu Y, Sun Y, Mao XO, Xie L, Greenberg DA. Vascular endothelial growth factor (VEGF) stimulates neurogenesis in vitro and in vivo. Proc Natl Acad Sci U S A. 2002;99(18):11946-50

54. Udo H, Yoshida Y, Kino T, Ohnuki K, Mizunoya W, Mukuda T, et al. Enhanced adult neurogenesis and angiogenesis and altered affective behaviors in mice overexpressing vascular endothelial growth factor 120. J Neurosci. 2008:28(53):14522-36

55. Pereira AC, Huddleston DE, Brickman AM, Sosunov AA, Hen R, McKhann GM et al. An in vivo correlate of exercise-induced neurogenesis in the adult dentate gyrus. Proc Natl Acad Sci U S A. 2007;104(13):5638-43.

56. Shetty AK, Hattiangady B, Shetty GA. Stem/progenitor cell proliferation factors FGF-2, IGF-1, and VEGF exhibit early decline during the course of aging in the hippocampus: role of astrocytes. Glia. 2005;51(3):173-86.

57. Leeman DS, Hebestreit K, Ruetz T, Webb AE, McKay A, Pollina EA, et al. Lysosome activation clears aggregates and enhances quiescent neural stem cell activation during aging. Science. 2018;359(6381):1277-83.

58. Stoll EA, Cheung W, Mikheev AM, Sweet IR, Bielas JH, Zhang J, et al. Aging neural progenitor cells have decreased mitochondrial content and lower oxidative metabolism. J Biol Chem. 2011:286(44):38592-601.

59. Beckervordersandforth R, Ebert B, Schäffner I, Moss J, Fiebig C, Shin J, et al. Role of mitochondrial metabolism in the control of early lineage progression and aging phenotypes in adult hippocampal neurogenesis. Neuron. 2017;93(3):560-573.e6.

60. Li L, Candelario KM, Thomas K, Wang R, Wright K, Messier A, et al. Hypoxia inducible factor-1a (HIF-1a) is required for neural stem cell maintenance and vascular stability in the adult mouse SVZ. J Neurosci. 2014;34(50): 16713-9.

61. Mazumdar J, O'Brien WT, Johnson RS, LaManna JC, Chavez JC, Klein PS, et al. $\mathrm{O} 2$ regulates stem cells through Wnt/ $\beta$-catenin signalling. Nat Cell Biol. 2010:12(10):1007-13.

62. Spritzer MD, Galea LA. Testosterone and dihydrotestosterone, but not estradiol, enhance survival of new hippocampal neurons in adult male rats. Dev Neurobiol. 2007;67(10):1321-33.

63. Hamson DK, Wainwright SR, Taylor JR, Jones BA, Watson NV, Galea LA Androgens increase survival of adult-born neurons in the dentate gyrus by 
an androgen receptor-dependent mechanism in male rats. Endocrinology. 2013;154(9):3294-304.

64. Okamoto M, Hojo Y, Inoue K, Matsui T, Kawato S, McEwen BS, et al. Mild exercise increases dihydrotestosterone in hippocampus providing evidence for androgenic mediation of neurogenesis. Proc Natl Acad Sci U S A. 2012; 109(32):13100-5.

65. Duarte-Guterman P, Lieblich SE, Wainwright SR, Chow C, Chaiton JA, Watson NV, et al. Androgens enhance adult hippocampal neurogenesis in males but not females in an age-dependent manner. Endocrinology. 2019; 160(9):2128-36.

66. Gould E, Woolley CS, McEwen BS. Adrenal steroids regulate postnatal development of the rat dentate gyrus: I. Effects of glucocorticoids on cell death. J Comp Neurol. 1991:313(3):479-85.

67. Cameron HA, McKay RD. Restoring production of hippocampal neurons in old age. Nat Neurosci. 1999:2(10):894-7.

68. Silva-Vargas V, Maldonado-Soto AR, Mizrak D, Codega P, Doetsch F. Agedependent niche signals from the choroid plexus regulate adult neural stem cells. Cell Stem Cell. 2016;19(5):643-52.

69. Kawaguchi D, Furutachi S, Kawai H, Hozumi K, Gotoh Y. Dll1 maintains quiescence of adult neural stem cells and segregates asymmetrically during mitosis. Nat Commun. 2013;4:1880.

70. Porlan E, Morante-Redolat JM, Marqués-Torrejón MÁ, Andreu-Agulló C, Carneiro C, Gómez-lbarlucea E, et al. Transcriptional repression of Bmp2 by p21 (Waf1/Cip1) links quiescence to neural stem cell maintenance. Nat Neurosci. 2013;16(11):1567-75.

71. Fu CH, lascone DM, Petrof I, Hazra A, Zhang X, Pyfer MS, et al. Early seizure activity accelerates depletion of hippocampal neural stem cells and impairs spatial discrimination in an Alzheimer's disease model. Cell Rep. 2019;27(13): 3741-3751. e4.

\section{Publisher's Note}

Springer Nature remains neutral with regard to jurisdictional claims in published maps and institutional affiliations.

Ready to submit your research? Choose BMC and benefit from:

- fast, convenient online submission

- thorough peer review by experienced researchers in your field

- rapid publication on acceptance

- support for research data, including large and complex data types

- gold Open Access which fosters wider collaboration and increased citations

- maximum visibility for your research: over $100 \mathrm{M}$ website views per year

At $\mathrm{BMC}$, research is always in progress.

Learn more biomedcentral.com/submissions 